

\title{
Vostell y su lectura contemporánea de la tragedia antigua. Reflexiones en torno a la obra 7 contra Tebas (1992)
}

\author{
Vostell and his Contemporary Reading of Ancient Tragedy. Reflections on the \\ Work 7 contra Tebas (1992)
}

\author{
Angélica García Manso \\ Universidad de Extremadura, Cáceres, España \\ angelicamanso@hotmail.es \\ http://orcid.org/0000-0002-9068-9379 \\ Recepción: 11/09/2019 | Aceptación: 13/03/2020
}

\begin{abstract}
Resumen
El presente estudio ofrece un análisis de 7 contra Tebas, obra del año 1992 en la que Wolf Vostell sintetiza tres de las claves estéticas más importantes que se dan a lo largo de su trayectoria creativa: la importancia de lo teatral, el Muro de Berlín como síntoma de lo humano y la imagen de la caída que encarna la figura mitológica de Ícaro -aunque Ícaro no sea partícipe de la obra de Esquilo que inspira la propuesta artística-. La composición, diseñada como proyecto para el Festival de Teatro Clásico de Mérida en paralelo con la propuesta de un faro de arte contemporáneo para las Islas Baleares -ambas fallidas al cabo-, se presenta con una rica polisemia en un contexto que sintetiza en buena medida el conjunto de la obra de Vostell desde sus inicios.
\end{abstract}

\section{Abstract}

This study provides an analysis of 7 contra Tebas (Seven Against Thebes), a 1992 work in which Wolf Vostell synthesizes three of the most significant aesthetic elements developed throughout his creative career: the importance of theatrical expression, the Berlin Wall as a sign of the human element, and the image of the fall embodied by the mythological figure of Icarus (despite the fact that Icarus is not featured in Aeschylus, as the text that inspired the artistic proposal). The piece was designed as a project for the Mérida Theatre Festival in parallel with the proposal for a contemporary art lighthouse in the Balearic Islands(both proposals failed). It is presented as a work of strong polysemy in a context that synthesises, to a large extent, the whole of Vostell's work from its beginnings.
Palabras clave

Wolf Vostell Composición en collage Escenografía teatral Interpretación mitológica Teatro romano de Mérida Muro de Berlín

Keywords

Wolf Vostell

Collage Composition

Theatrical Scenery

Mythological Interpretation

Roman Theater in Merida,

Spain

Berlin Wall 


\section{Introducción: La imagen del avión como happening en suspenso en Wolf Vostell}

El componente teatral constituye un ingrediente indispensable del happening y, por descontado, también del happening que se concreta en el movimiento Fluxus. En efecto, Fluxus parte de la premisa de una voluntad artística que es interdisciplinar por definición, aunque la obra resultante no necesariamente haya de ser improvisada en el sentido de carente de reflexión previa, pues obliga también a acotar espacios para los gestos y los sonidos, sean estos reales o sugeridos por objetos o imágenes'. Y es que, de alguna manera, la intención que refleja la representación teatral en el contexto del arte contemporáneo a través del movimiento o arte Fluxus es doble: de un lado, la propuesta expositiva de un acontecimiento único, imposible de repetir salvo que sea en el marco de lo teatral; $y$, de otro, la fijación de un momento que es dinámico, pues solamente el movimiento cíclico o el fondo musical pueden ser motivos subsidiarios de la detención del instante. En esa doble intención, por reduccionista que resulte a primera vista, descansa en buena medida la aportación de Wolf Vostell (1932-1998)² al citado movimiento $y$, sobre todo, a la estética que plantea el artista alemán acerca del suceso o acontecimiento y, al tiempo, acerca de la imposibilidad de registrarlo, en una tensión que surge de hechos biográficos condicionados por el peso histórico de la persecución antisemita y de la II Guerra Mundial en Alemania. De acuerdo con ello, la representación se convierte en la vía abierta para la percepción de un fenómeno o idea, pero también una representación necesita ser virtualmente fijada, sea mediante grabado, o fotografía, sea recompuesta o reconsiderada mentalmente o a través de las anotaciones previas a su puesta en escena, para poder subsistir en el tiempo, aunque sea "re-representándose" a sí misma en bucle.

En un sentido en cierta forma inverso, Vostell también desarrolla una propuesta estética que denomina decollage, dé-collage o dé-coll/age, la cual se presenta a ojos del artista alemán como el reverso más exacto del proceso de fijación y dinamismo en el tiempo que se encarna en los happenings ${ }^{3}$. Y es que, mediante la rasgadura característica del procedimiento creativo del decollage, se produce la negación del tiempo,

1. Cf. Harry Ruhé, Fluxus. The most radical and experimental art movement of the sixties (Amsterdam: A Verlag, 1979); Owen Smith, Fluxus: The History of an Attitude (San Diego, CA: San Diego State University Press, San Diego, 1998); Moisés Bazán de Huerta, ed., Simposio Happening, Fluxus y otros comportamientos artísticos de la segunda mitad del siglo XX (Cáceres: Editorial Regional de Extremadura \& Universidad de Extremadura, 2001).

2. Vid. como visión de conjunto María del Mar Lozano Bartolozzi, Wolf Vostell (Donostia-San Sebastián: Nerea, 2000).

3. Cf. Josefa Cortés Morillo, "Wolf Vostell: El concepto de "de-coll/age" en sus libros de artista," en Libros con Arte. Arte con Libros, eds. María del Mar Lozano Bartolozzi et al. (Cáceres: Consejería de Cultura y Turismo de la Junta de Extremadura, 2007), 207-221. 
pues el rasgado descubre que lo que se oculta únicamente es comprensible desde la cronología, desde la presencia de capas del pasado que retornan al presente mediante el acto artístico. Además, se trata de un momento perenne, pues parece permanecer al preexistir antes del rasgado. En otras palabras y grosso modo, Fluxus y decollage se complementan como anverso y reverso de la reflexión del artista acerca del tiempo: repetido en su fluir o reiterado en su detenimiento ${ }^{4}$.

De acuerdo con estas premisas de índole abstracta, la imagen del avión en vuelo ofrece una síntesis más concreta de las especulaciones sobre el tiempo y su percepción: en efecto, un vuelo no se puede detener, pues el avión caería en picado y, al tiempo, como en la clásica paradoja de Aquiles y la tortuga ${ }^{5}$, el movimiento se presenta como una suma de instantes que pueden llegar a representarse en imágenes concretas, más aún cuando dichos momentos se pueden hacer coincidir con bombas que se dejan caer verticalmente. Por lo demás, el ruido se convierte en elemento intrínseco de la representación de un avión en vuelo, a pesar de que no sea audible en una obra estática, pues solamente lo sería en un happening o representación Fluxus.

En Vostell la iconografía del avión ${ }^{6}$ se postula también como la idea trágica del bombardero: el vuelo y las bombas arrojadas son imposibles de detener y, al tiempo, la destrucción que provoca resulta instantánea, perceptible a la vez que permanente y objetivable en una representación trágica. Son numerosas las obras de Wolf Vostell que combinan avión de guerra y desolación, aunque en ocasiones esta surja de un contraste que nace de la ironía; tales creaciones abundan sobre todo en forma de fotocollage. Entre las creaciones más conocidas se cuentan: el collage Flower Power ${ }^{7}$, o los assemblages de técnica mixta LippenStift-Bomber ${ }^{8}$ y Projekt: B52-Einbetonierung ${ }^{9}$, entre otros. Pero la tradición gráfica en torno al avión que cae verticalmente como una cruz encarna al propio artista desde algunas de sus primeras pinturas, como Kriegskreuzigung I y $\|^{10}$, y adquiere una naturaleza física en la célebre escultura ¿Por qué el proceso entre Pilatos y Jesús duró solo dos minutos?"1, en el que el cazabombardero se presenta iconográficamente como

4. Cf. Marlen Vogel, Das illusorische Theater und die Kunstbewegungen Happening und Fluxus (München: Grin Verlag, 2007).

5. Cf. Santiago Echandi Ercila, La fábula de Aquiles y Quelone: Ensayos sobre Zenón de Elea (Zaragoza: Prensas Universitarias de Zaragoza, 1993).

6. Vid. José Julio García Arranz, "El azar como resemantizador de la obra de arte: A propósito de '¿Por qué el proceso entre Pilatos y Jesús duró sólo dos minutos?," Norba-Arte, no. 27 (2007): 217-242. El estudio de García Arranz ofrece al respecto de la iconografía del avión en Wolf Vostell una rica bibliografía comentada.

7. 1968, Städelscher Museums, Frankfurt am Main.

8. 1968, Neues Museum, Nürnberg.

9. 1970, Smart Museum of Art of the University of Chicago.

10. 1953, guache y óleo respectivamente, Colección Mercedes Vostell, Malpartida de Cáceres.

11. 1996-1997, Museo Vostell Malpartida, Malpartida de Cáceres. 


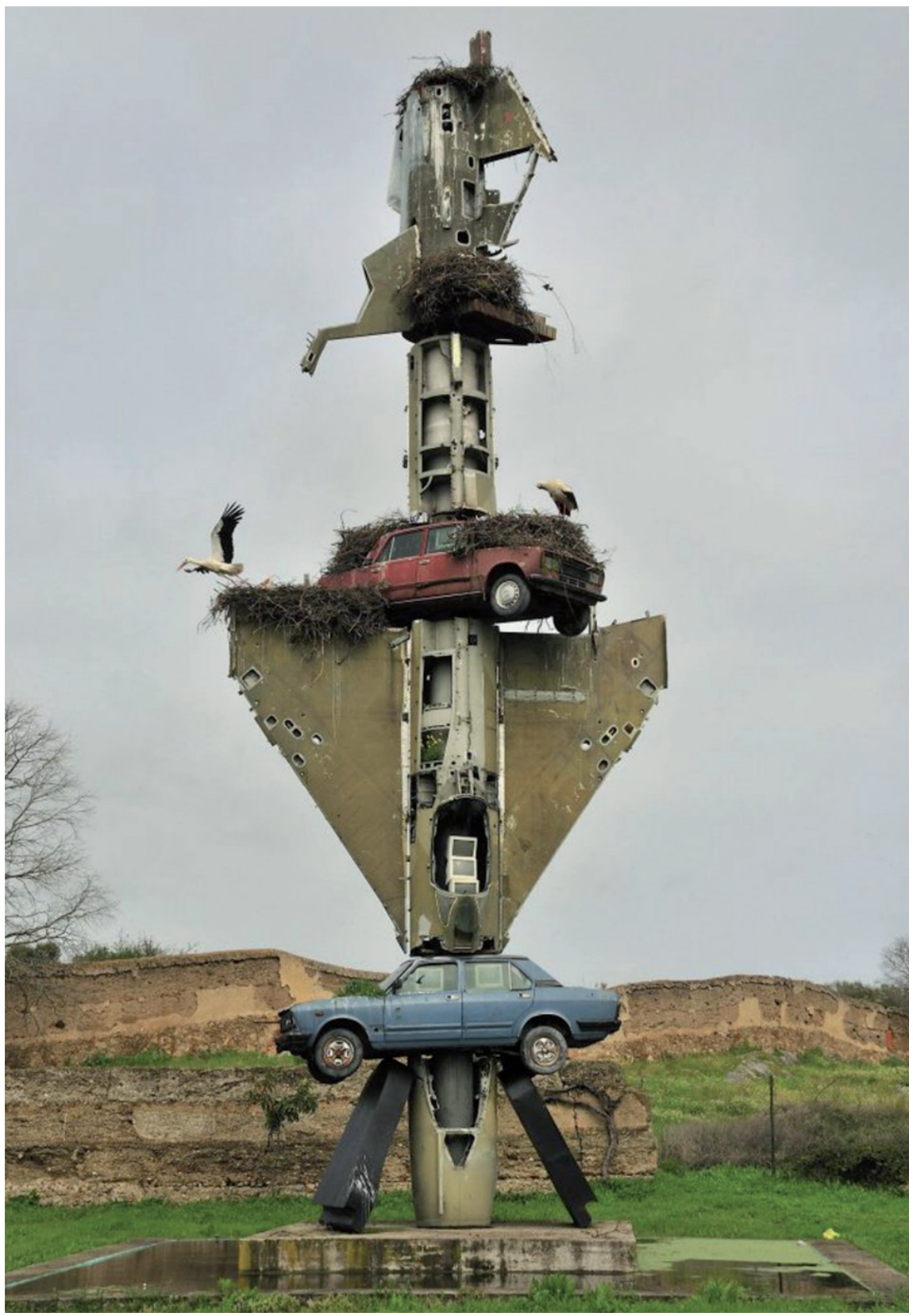

Fig. 1. Instalación ¿Por qué el proceso entre Pilatos y Jesús duró sólo dos minutos?, 1996-1997. Museo Vostell Malpartida, Malpartida de Cáceres. metáfora del crucificado ${ }^{12}$. Se trata, en fin, de obras en las que se evoca la II Guerra Mundial, tan presente en la creatividad alemana de posguerra, pero también se proyecta esta hacia las guerras surgidas con posterioridad: Corea y Vietnam más en concreto y de una manera fuertemente icónica y, finalmente, sobre la Guerra Fría y su final. Por lo demás, el recurso al "pintalabios-bomba", al margen de la ironía que implica, denota también que la guerra encarna un proceso de imposición sexual, presente en el collage Flower Power anteriormente citado, y convierte a Vostell en un auténtico poeta visual ${ }^{13}$.

En este contexto llama poderosamente la atención una obra que ofrece una posición de centralidad al avión de combate, como la que va a ser objeto de análisis en el presente estudio, como síntesis de la trayectoria de Vostell aplicada a la escenografía. Se trata de 7 contra Tebas (1992), con un título en español que, además de insertar un guarismo en lugar de su desarrollo alfabético, es síntoma preciso de que adquiere sentido en la colección del artista en Malpartida de Cáceres ${ }^{14}$. En dicha obra predomina de nuevo un tema bélico mediante el que Vostell reaprovecha la figura del avión cazabombardero para referirse a un texto clásico del teatro antiguo,

12. Aunque cabe también una lectura irónica en paralelo con la figura de ĺcaro que analizaremos en epígrafes posteriores. Tal lectura se refiere a la duración de la caída en picado de un avión y la escena evangélica del corto interrogatorio sucedido entre el gobernador romano y el mesías cristiano. Cf. también Dieter Ronte, "Kriegskreuzigung/War Crucifixion," en Wolf Vostell. Meine Kunst ist der ewige Widerstand gegen den Tod. Katalog, ed. Gabriele Ueisberg (Bonn: Rheinisches LandesMuseum, 2007), 6-9.

13. Cf. Josefa Cortés Morillo, "Obra gráfica de Wolf Vostell (1959-1979)," Norba-Arte, no. 22-23 (2002-2003): 239-260.

14. Vid. García Arranz, "El azar como," nota 35, en la que se reproduce un interesante e irónico pasaje de Vostell acerca de la carga estética y la imagen majestuosa que aportan los aviones de combate. 
a una de las obras del dramaturgo griego Esquilo, a la vez que utiliza como fondo un entorno fotografiado, en el presente caso el frente o scenae frons del teatro romano de Mérida, como corresponde, además, con un tema procedente de la Antigüedad Clásica.

Por otra parte, 7 contra Tebas constituye una propuesta artística que es coetánea de la serie de obras titulada ĺcaro y Tanit, cuyo eje es, de nuevo, el avión de combate. Se

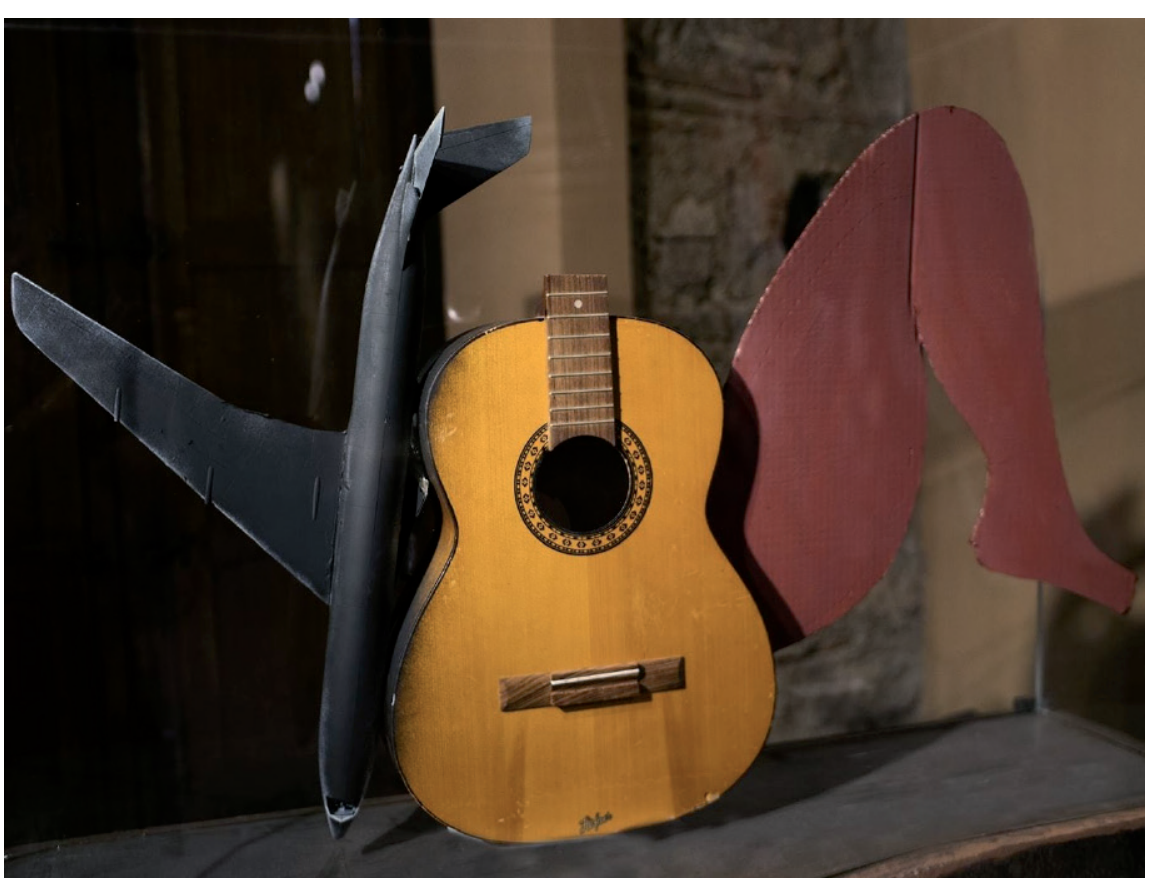

Fig. 2. Ícaro y Tanit VII, 1992. Museo Vostell Malpartida, Malpartida de Cáceres. trata de una serie con la que la obra para el teatro emeritense mantiene un evidente contacto, aunque 7 contra Tebas no pertenece strictu sensu a dicha serie, entre otros motivos porque en apariencia los referentes mitológicos son literalmente distintos. Por otra parte, también se trata de un ciclo que Vostell desarrolló en el mismo período de los años 1992-1993 en el contexto de la propuesta de un faro para la isla de Formentera, que nunca llegó a construirse por motivos de legislación del medio ambiente ${ }^{15}$.

En la serie Ícaro y Tanit Vostell se basa en una idea que depura a partir de una composición en la que juega con tres elementos: un avión, una pierna recortada y un tercer objeto, que puede ser un botellín de una célebre bebida de refrescos, unas copas de cristal, una guitarra sin mástil o un artefacto eléctrico como una aspiradora, etcétera, del elenco de motivos como coches o vagones ferroviarios que son propios de su repertorio creativo; todo ello mediante una combinación en la que Ícaro representa el avión o elemento masculino y Tanit la pierna abierta o femenina. Entre uno y otro motivo se interpone el encuentro, cargado de carácter fálico del avión sobre la vulva, la cual a su vez se carga de ironía a partir de los elementos antes citados. Por lo demás, Tanit se asocia como divinidad púnico-fenicia a las Islas Baleares, de forma que es el encargo el que invita a concebir la figura de un faro como una mujer a partir de los icónicos logotipo y botella de Coca-Cola, que figura también en decollages como el que presenta un

15. Cf. Andreu Manresa, "Obras Públicas desautoriza un proyecto plástico en faros de Ibiza al día siguiente de su presentación," El País, 25 de septiembre de 1992, consultado el 3 de junio de 2019, https://elpais.com/diario/1992/09/25/cultura/717372004_850215.html. 
título homónimo de la conocida marca de refrescos, del año 1961, expuesto en el Ludwig Museum Köhln. Pero la deidad antigua se ofrece también como un aspirador electrodoméstico, con el doble sentido de aspirar los barcos y de encarnar la vivencia del hogar a la manera homérica de Ítaca, por ejemplo. 0, por señalar un tercer eco semántico, Tanit se ofrece como la tierra en la que se incrusta un falo -el avión-, con la polisemia que de ello se deriva en el eje mar-tierra-aire en el que interviene un faro. En fin, pocas divinidades antiguas han sido reducidas a un mínimo conceptual de un símbolo como sucede con Tanit, pues su representación gráfica ofrece un esquematismo geométrico que de alguna manera repite de forma inconsciente Vostell en las tríadas compositivas de la serie al sumar la pierna femenina al avión más un tercer objeto, de forma que el artista termina invocando el símbolo fenicio incluso en el aspecto trapezoidal que confiere su propuesta de intervención sobre la escena de Mérida.

Derivado de todo ello se descubre un proceso de "resemantización", según conceptualiza García Arranz ${ }^{16}$, del icono del avión de guerra, que desde su condición de denuncia antibélica se transforma en mitología de la caída del ser humano sobre la tierra madre, sobre la feminidad matriz, como máximo ejemplo del fracaso que constituye la guerra: un atentado contra la esencia humana, contra lo que nos define como especie. Y es que, desde una perspectiva mitológica ya totalmente clásica o grecolatina, la iconografía de la caída responde al arquetipo de ĺcaro: el avión derribado, clavado de morros en el suelo, reproduce el fallido vuelo del héroe antiguo al acercarse al sol ${ }^{17}$.

\section{7 contra Tebas como póster y como escenografía teatral}

La influencia Fluxus otorga una enorme potencia escenográfica al trabajo de Vostell, más aún en lo que se refiere a los motivos del avión derribado en composición con unas piernas femeninas y a las figuras mitológicas que se descubren en su trayectoria estética y que se hacen más patentes aún en la etapa final del artista. Ciertamente, sin tales referentes no resulta posible comprender la profundidad de sentido que, según se va a analizar en los

16. García Arranz, "El azar como." Cf. también Lozano Bartolozzi, Wolf Vostell, 100.

17. Por lo demás, resulta enormemente sugerente conectar temas vostellianos como los de Ícaro, el avión clavado, la fecundación de la tierra femenina, etcétera, con planteamientos cinematográficos como, por citar dos referentes clave en la historia del cine alemán, Wim Wenders en lo que se refiere concretamente a la imagen del ángel caído que sintetiza la película El cielo sobre Berlín (Der Himmel über Berlin, 1987), que casi coincide cronológicamente con la serie Ícaro y Tanit, o Werner Herzog, en un filme como Fata Morgana (1971), en el que la iconografía del avión derribado se hace presente con enorme potencia visual, en una propuesta que influirá también en la película The Being of Earth/El ser de la tierra (1990), de David Vostell, hijo del artista, filme que, de nuevo, casi coincide en el tiempo con la obra objeto de análisis y con las series y creaciones coetáneas. 
Fig. 3.7 contra Tebas, 1992. Museo Vostell Malpartida, Malpartida de Cáceres.

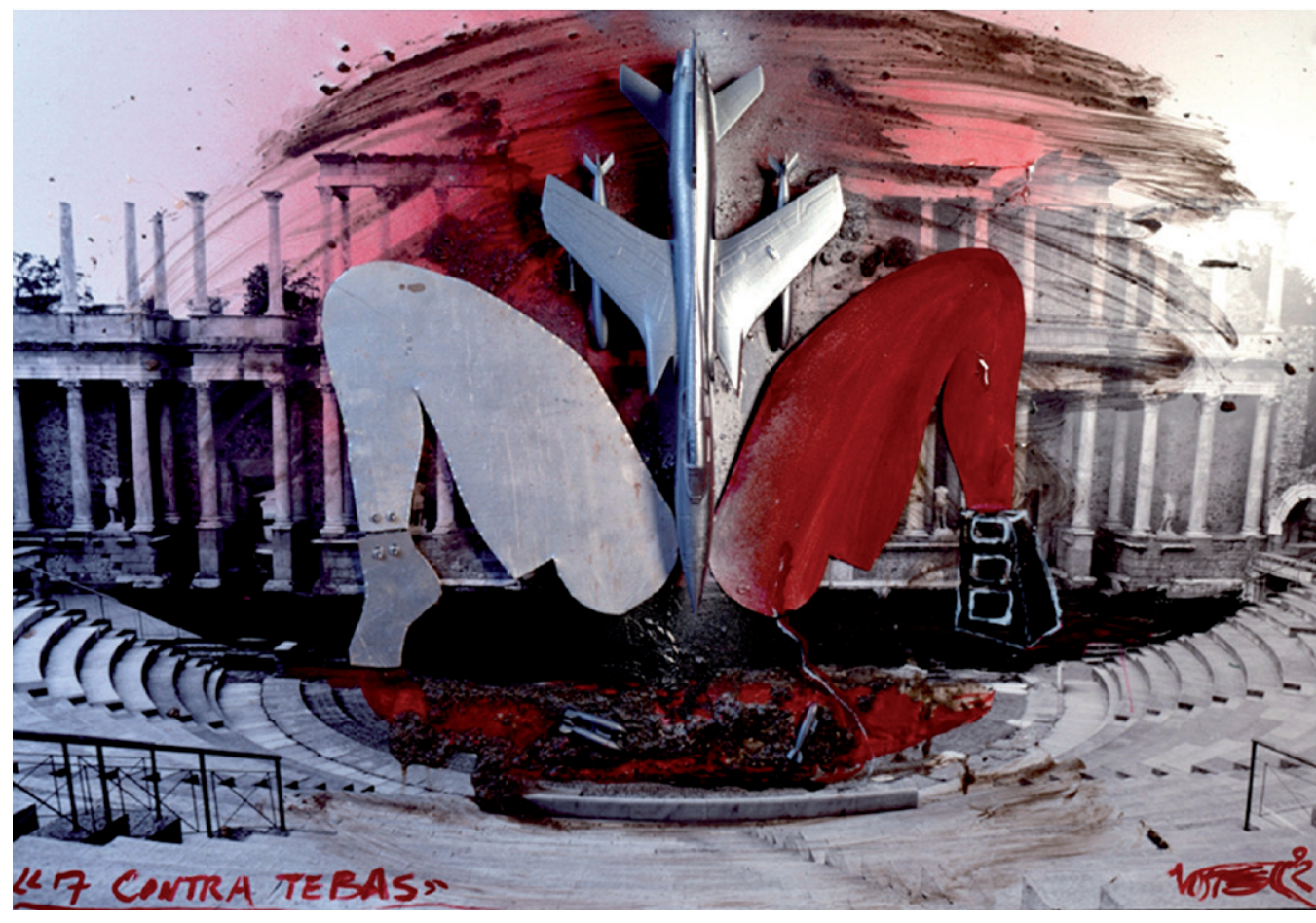

próximos epígrafes, ofrece la composición 7 contra Tebas, con una doble finalidad: como concepción para el espacio escénico o como proyecto de diseño para un cartel.

De todo lo expuesto se desprende que la composición 7 contra Tebas no constituye un fin en sí misma, dado que, además de ser paralela y fuertemente concomitante con la serie ĺcaro y Tanit, es en realidad fruto de un encargo, sea como diseño de un póster, sea como propuesta de un fondo escenográfico para la representación ${ }^{18}$. Se da la circunstancia de que Vostell es creador de carteles para happenings y, en el ámbito teatral propiamente dicho, colabora con el prestigioso director Hansgünther Heyme, también alemán, tanto en lo que se refiere a pósteres y portadas de libros como en las escenografías para la representación teatral. A este respecto, se trata de libros en los que Heyme presenta las realizaciones dramáticas que lleva a cabo, entre las que se cuentan obras de Shakespeare y del escritor británico de origen paquistaní Tariq Alí así como adaptaciones de Goethe y, sobre todo, dados los vínculos que guardan con el mundo clásico greocolatino, la puesta en escena de La muerte de Empédocles, de Friedrich Hölderlin, obra que recrea en forma de monólogo en verso una visión romántica del antiguo filósofo griego y su relación con la naturaleza antes de arrojarse al Etna a la vez que ofrece nuevamente la idea de caída; y, en fin, ya con un carácter plenamente dramatúrgico, Vostell es autor del póster de Las Fenicias, de Eurípides, y de Los Pájaros, de 
Aristófanes, en adaptación de Heyme y cuyas tramas, ahora sí, sobre todo en relación con la primera, guardan una mayor relación con Los siete contra Tebas de Esquilo.

En los carteles que Vostell plantea, a propósito de las versiones teatrales de Heyme, el personaje de la obra de Shakespeare se presenta como un maniquí femenino destrozado ${ }^{19}$ cuyo rostro cubre una máscara de la I Guerra Mundial y con la pantalla de un pequeño televisor que tapa su pubis; es decir, el póster ofrece motivos estéticos del pintor perfectamente reconocibles en un collage inicialmente tridimensional que remarca el carácter polisémico de la obra. Para el texto de Tariq Alí, Vostell recurre también a un fotocollage tridimensional para el que emplea como trasfondo fotogramas de un filme clásico de Serguei M. Eisenstein al que añade relieve mediante un pan con un termómetro clavado, en tanto que para el Fausto de Goethe el pintor interviene sobre unas fotografías de enfrentamiento policial que repite y estratifica a lo largo del espacio, que rompe con un recorte en color de unas piernas femeninas desnudas. Más difuso resulta lo relativo a la obra de Eurípides, dado que Vostell parte de un collage surrealista, donde la cabeza de un ave se superpone sobre el busto de la Venus de Milo ${ }^{20}$; lo mismo sucede con el cartel de la comedia aristofánica, que se presenta a partir de un discóbolo caído o, en el mismo ámbito deportivo, como el inicio de una carrera contemporánea de atletismo. En fin, el trabajo sobre el texto de Hölderlin es ante todo escenográfico, y es de dicho planteamiento de donde se extrae la iconografía de la obra²1.

En el caso concreto de 7 contra Tebas se da por descontado que la fuente de inspiración es Esquilo, más específicamente la preparación para la representación de la obra en el Festival de Teatro Clásico de Mérida (Badajoz) en el año 1992²2. En relación con la escenografía y frente a lo que sucede en el happening, que es por definición dinámico, la propuesta ofrece un estatismo próximo al de la pintura; o, en otras palabras, el artista afincado en Malpartida de Cáceres aborda el encargo como si interviniera sobre una superficie plana, cegando los accesos frontales del frente de columnas conocido como valva regia.

19. Se trata de un concepto que procede de un happening anterior, que incluso aparece como portada del libro de Jürgen Becker y Wolf Vostell, Happenings. Fluxus. Pop Art. Nouveau Realisme. Eine Dokumentation Herausgegeben (Reinbeck bei Hamburg: Rowohlt Taschenbuch Verlag, 1965).

20. Vid. Hansgünther Heyme y Wolf Vostell, Hamlet. Phöenizierinnen. Inszenierungsdocumentation (Stuttgart: Württembergische Staatstheater Stuttgart \& Druckhaus Münster, 1982).

21. Vid. Marco Castellari, Hölderlin und das Theater: Produktion - Rezeption - Transformation (Berlin: De Gruyter, 2018), 473.

22. Vid. Antonio Franco Rodríguez, José Antonio Agúndez García, y Javier Cano Ramos, Vostell Extremadura (Mérida: Asamblea de Extremadura, 1992), 29. 
Se trata de unos momentos en la historia del Festival de Mérida, a caballo entre las décadas de los años 80 y 90, en que sus responsables buscan su proyección exterior mediante la celebración de congresos y ediciones de las versiones representadas; pero, al mismo tiempo, se busca remarcar una personalidad interior con la participación de creadores y artistas de origen extremeño o asentados en Extremadura. En el caso de la obra de Esquilo se contó con la adaptación de la obra llevada a cabo por el escritor Jesús Alviz a partir de la versión preparada previamente por parte de Concha Rodríguez, filóloga clásica y realizadora teatral, a la vez que se representó bajo la dirección de Paco Suárez ${ }^{23}$, con la veterana Florinda Chico como una de las actrices de reclamo, en una producción de la organización con un marcado carácter regional ${ }^{24}$, pues todos ellos son extremeños. Pero al final, a pesar del encargo y de estar afincado en Extremadura, Vostell no interviene en el diseño para la representación, para la que se termina prefiriendo la intervención creativa de Eduardo Úrculo ${ }^{25}$, quien propugna un escenario desnudo con proyecciones lunares como uno de sus elementos más llamativos, a la vez que, mediante la iconografía de maletas dispersas por el espacio de la escena, teniéndose en cuenta, además, que las maletas son un elemento fuertemente característico de su estética artística, se prestaba un homenaje al asedio de Sarajevo que, en plena guerra de Yugoslavia, se estaba produciendo en el momento de la representación.

En este contexto, al margen de la radicalidad de la propuesta de Vostell, de haberse aplicado sobre un lugar de protección monumental y arqueológica, existe un contexto que el artista alemán sabe trasladar a su proyecto, hasta el punto que su composición supera la condición de póster o de escenografía para, y he aquí el objeto de nuestro análisis, convertirse en hermenéutica del texto de Esquilo, cosa que resulta más forzada en la interpretación sobre el conflicto de los Balcanes que propugna Úrculo en la escenografía finalmente adoptada. Y es que Vostell, a partir de su personal trayectoria poética, actúa como intérprete del drama que asola una ciudad en su interior (dado el carácter fratricida con el que el artista alemán aborda no solamente los traumas derivados de la II Guerra Mundial, sino los de cualquier guerra ${ }^{26}$ ).

23. Paco Suárez se convertirá tres lustros después en director del Festival.

24. Esquilo, Siete contra Tebas, versión y trad. Jesús Alviz Arroyo, E. Díez-Canedo, y Concha Rodríguez (Madrid: Ediciones Clásicas, 1992).

25. Vid. Manuel Palomino Arjona, Dramaturgia asturiana contemporánea. Índice biobibliográfico (Morrisville, North Caroline: Lulu Press, Lulu. com, 2019), 291.

26. También la de los Balcanes de los años 90 del pasado siglo, ejemplificada en Sarajevo, ciudad mártir a la que Vostell dedicó una serie de conciertos Fluxus de los que se editaron diferentes litografías, algunas con fuselajes de aviones; vid. García Arranz, "El azar como," nota 27. 
En efecto, la tragedia de Los siete contra Tebas formaba parte de una tetralogía de Esquilo de la que no se conserva nada más que esta obra, acerca de un acuerdo roto sobre la sucesión del poder en Tebas; es decir, de un desacuerdo político que deriva en enfrentamiento militar sintomáticamente representado en las defensas de las siete puertas de la ciudad y, más en concreto, como desarrollo de la trama trágica, en aquella en la que se enfrentan los hermanos Eteocles y Polinices, hijos los dos de Edipo ${ }^{27}$. De cualquier forma, se trata de un acontecimiento que no es puntual, sino fruto de un infortunio abordado en forma de serie -disposición que fue inaugurada con la trilogía dedicada a la Orestíada por el mismo Esquilo- acerca de la maldición que afecta a los Labdácidas o descendientes de Edipo. Así, el relato que sucede naturalmente a los acontecimientos que se describen en la obra es el de Antígona, personaje ya presente en la obra de Esquilo, pero que la tradición occidental conoce mejor a través del título con el nombre de la heroína obra de Sófocles, que constituye uno de los hitos de la cultura occidental ${ }^{28}$. En efecto, probablemente sea Antígona la personalidad cuya presencia se anuncia en la creación de Vostell, pero su figura aparece hibridada con la de Ícaro, como una suma de lo femenino (Antígona y Tanit) y de lo masculino (Ícaro), es decir, con un motivo mitológico ajeno al ciclo tebano y que, en realidad, lo que hace es incardinar una obra puntual con una de las inquietudes estéticas que le ocupan en ese momento, según hemos señalado ya.

En este contexto, las dos piernas de Antígona se pueden leer en la clave de los hermanos enfrentados, y se plasman con colores opuestos, a la vez que convergen en el gozne del avión, con un evidente carácter fálico que deriva en destrucción y no en vida, en una especie de alumbramiento de una placenta sin que previamente se haya producido nacimiento.

La descripción de la obra se puede hacer en los siguientes términos: sobre un fondo de plancha metalizada que reproduce en superficie plana y forma entelada, una fotografía de la scaenae frons del teatro romano de Mérida y parte de sus gradas laterales y las primeras de las centrales se instalan los siguientes elementos, que, a su vez, aparecen coloreados a base de brochazos sobre el citado fondo, como un celaje rojizo y rosáceo en calidad de ominosa amenaza cruenta, además de sombrío: un avión de caza o combate clavado verticalmente en la bisectriz de unas piernas femeninas abiertas, que ocupan el corazón o motivo central de la imagen, y de la que mana una masa informe de bombas y un amasijo de restos de destrucción sobre una enorme mancha roja y negra de pintura

27. Alan H. Sommerstein, Aeschylean Tragedy (London: Duckworth, 2010). Cf. también el tratamiento interartístico presente en las distintas aportaciones aparecidas en Isabelle Torrance, ed., Aeschylus and War: Comparative Perspectives on Seven against Thebes (London \& New York: Routledge, 2017).

28. Georges Steiner, Antígonas. Una poética y una filosofía de las lecturas (Barcelona: Gedisa, 1996). 
gruesa que ocupa el conjunto de la orchestra. A su vez, con colores alternos u opuestos, entre el rojo y el cromado o metalizado, y de forma acorde con el blanco y negro de la fotografía y el barniz del avión, aparecen recortadas las dos piernas femeninas en forma de triángulo invertido, cuyos pies aparecen marcados, sea por dos juegos de remaches en el caso del pie izquierdo, sea por haberse transformado en una especie de peso de balanza o contrapeso, en una peana negra escalada o en un oscuro archivador de cajones de inspiración daliniana -cuya obra conoce Vostell, además de haber tratado personalmente al artista de Figueres-, si bien la forma trapezoidal posee una clave interna en la creación de Vostell, toda vez que se presenta como parte de un muro que se rompe a la manera de la caída del Muro de Berlín, que tanto impactó al artista. De esta manera, la idea de puerta que ofrecen las piernas de la mujer aparece simbólicamente reforzada con un elemento que enraíza fuertemente al suelo la escena, a la vez que termina otorgando al conjunto cierto aire surrealista. Finalmente, en los ángulos inferiores, en rojo, el título 7 contra Tebas, en español y con guarismo, y la firma del pintor en el mismo tono y brocha.

\section{Conclusión: Tebas, Berlín y la puerta enfrentada}

Pintura occidental y mitología clásica constituyen expresiones casi sinonímicas. No es algo extraño en Vostell, por descontado ${ }^{29}$. Sin embargo, en el caso del trabajo del artista alemán sí responde a un abordaje netamente original a partir de sus propuestas de composición y decollage, pues arranca jirones del relato para descubrir otros inconexos en principio, pero que se "resemantizan" en el propio proceso, tal como sucede con las figuras de Ícaro-Antígona en la obra objeto de análisis; o, cuando menos, responde a un proceso de deconstrucción que el artista alemán hace de la tradición mitológica -y, en general, cultural-, cuya lectura última busca transformar. Por lo demás, cualquier obra exige una contextualización precisa; en 7 contra Tebas dicha contextualización adquiere entidad en Mérida, donde se hace ubicar una historia como la de Esquilo con el centro ocupado por un avión de guerra que parte en dos, como un gozne, la dualidad no solo sexual de la naturaleza, sino de la guerra. La dualidad está presente en la tragedia originaria, en una guerra fratricida, dado que para Vostell toda guerra es una guerra civil, pero también se encuentra en la poética del artista, según hemos considerado a propósito de la iconografía del avión desde los inicios de su carrera creadora.

29. Vid. Franco Rodríguez et al., Vostell Extremadura, 189-197. Cf. también Wolf Vostell, Impresiones. La colección de obra gráfica del Archivo Happening Vostell del Museo Vostell Malpartida. Catálogo (Mérida y Malpartida de Cáceres: Editora Regional de Extremadura y Consorcio del Museo Vostell Malpartida, 2008), 53. 

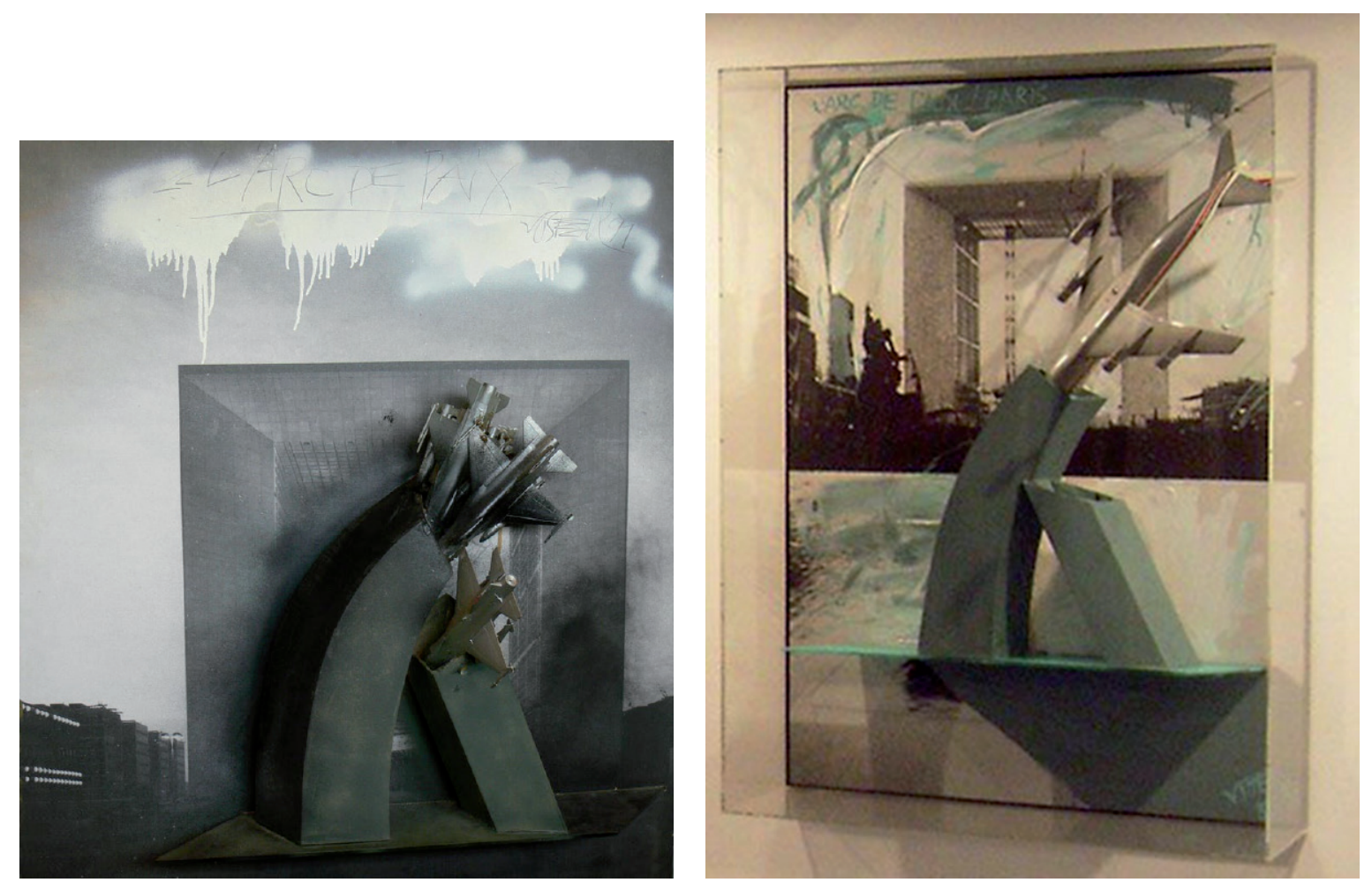

Figs. 4 y 5. Dos versiones de L'Arc de Paix 1991. Actualmente en colecciones particulares. (Fotografías tomadas de https://www.1stdibs.com/art/mixed-media/ wolf-vostell-art-installation-l-arc-de-paixarch-peace-wolf-vostell/id-a_322352/ y http://www.galerie-baecker.de/kuenstler/ vostell/I_arc.HTML, consultado el 5 de mayo de 2019).

Para ello, a partir de la figura de Ícaro, quien no aparece en el texto de Esquilo ni guarda relación con la serie de infortunios que asola al desgraciado Edipo y a la estirpe de los Labdácidas de la que este forma parte, Vostell construye un imaginario de la caída que es, al cabo, la caída del hombre frente a la mujer, o de la civilización ante la naturaleza. Así, es la libertad creativa de Vostell la que le permite llevar a su estética la historia de un personaje con un nombre propio que, como el de Edipo, etimológicamente se refiere a la cojera; también le permite llevar a sus claves artísticas recreaciones de letras griegas lambdas, de símbolos de Tanit, etcétera. El avión de combate que desestabiliza un entorno arquitectónico reconocible, más si cabe tratándose de puertas, está presente en otras obras, como L'Arc de Paix, de la que, además de bocetos a lápiz, existen al menos dos versiones, elaboradas entre los años 1989 y 1991 y en la actualidad en colecciones privadas tras ser subastadas. En sendas composiciones de L'Arc de Paix sobre un fondo idéntico (el arco de la Défense o Grande Arche, en París), se muestran en un caso tres cazas estrellándose contra el soporte que imita el hormigón y en el otro un único avión de mayor envergadura ${ }^{30}$; en las dos obras los aviones se incrustan contra una estructura con forma de lambda, según hemos apuntado ${ }^{31}$.

30. Hans-Peter Riese, "Arc de Paix," en Wolf Vostell. Meine Kunst ist der ewige Widerstand gegen den Tod. Katalog, ed., Gabriele Ueisberg (Bonn: Rheinisches LandesMuseum, 2007), 96-97.

31. Cf. también García Arranz, “El azar como,” nota 24. 
Pero lo realmente interesante no es tanto la referencia al arco-puerta, sino cómo en 7 contra Tebas se produce una elaborada síntesis de la trayectoria creativa de Vostell con la singular interpretación que hace del mito en torno a la muerte de los hijos de Edipo en Tebas. De hecho, tal concepto constituye el leit-motiv principal de su lectura de la caída del Muro de Berlín plasmado en una de las obras señeras de su última etapa: Mythos Berlin ${ }^{32}$. En efecto, la desaparición del Muro convierte todo lo relacionado con el trabajo de Vostell en torno al hormigón a lo largo de décadas en un imaginario propio ${ }^{33}$ en el que el artista encuentra correspon-

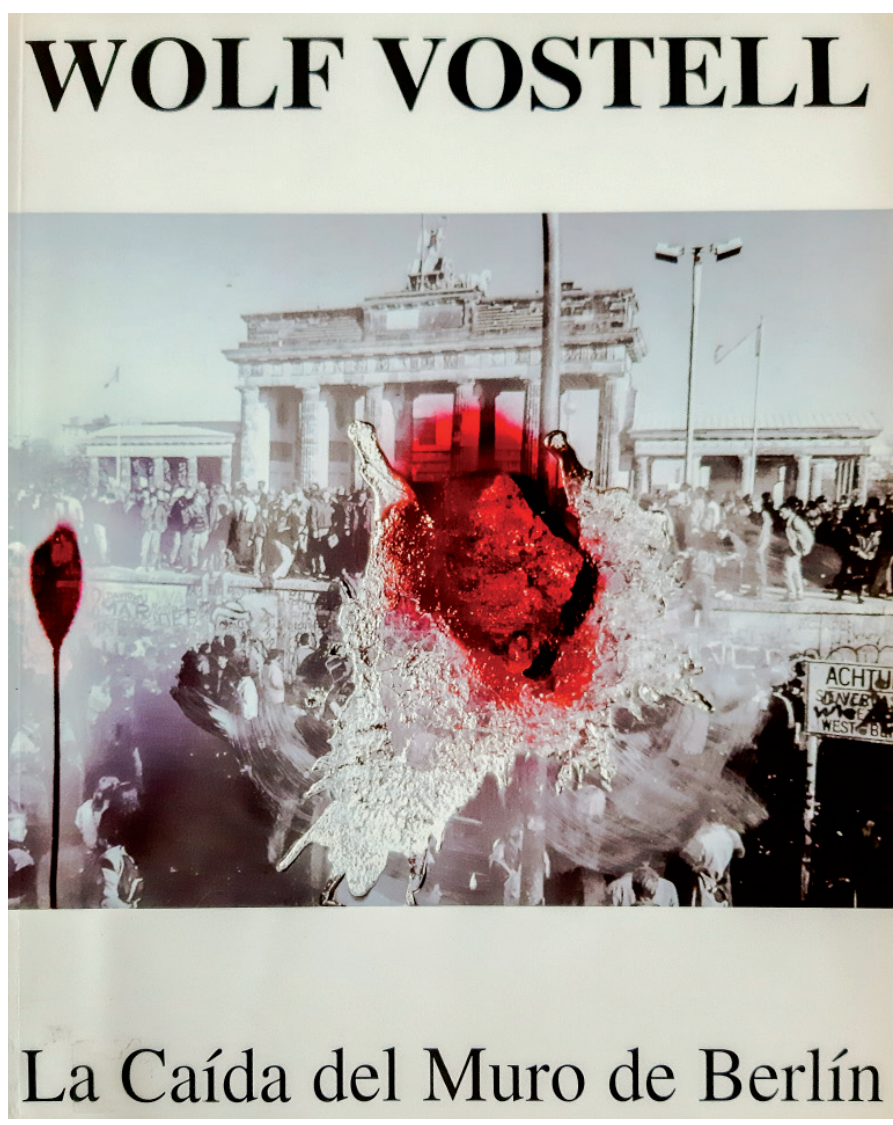

Fig. 6. Portada del libro La caída del Muro de Berlín, de Wolf Vostell. dencias entre Berlín y las murallas tebanas ante las que mueren los hijos de Edipo, con predominio de un fondo rojo vibrante, aunque, ciertamente, carece del motivo del avión, que el pintor desarrollaría sobre todo, según hemos visto, con la serie ĺcaro y Tanit.

Es en ese marco donde encuentra sentido unos de los pies metamorfoseado en archivador, en calidad de pieza del Muro y del sistema de la antigua República Democrática Alemana, tal como aparece recreado en la obra Corazón de piedra ${ }^{34}$, que sirve de portada al libro La caída del Muro de Berlín, publicado póstumamente ${ }^{35}$ y fruto de una exposición sobre el trabajo de Vostell en torno a dicho acontecimiento histórico. Derivado de todo ello se puede descubrir cómo la puerta de Tebas en la que tiene lugar el enfrentamiento entre los hijos de Edipo es también la Puerta de Brandenburgo en Berlín, o, si

32. 1987, Museo Vostell Malpartida, Malpartida de Cáceres.

33. Por lo demás, el hormigón armado que se transmuta en volumen escultórico había sido empleado repetidamente por Vostell con intervenciones paisajísticas en el entorno de Las Barruecos, de Malpartida de Cáceres, así como en estructuras decorativas en ciudades europeas. De alguna manera, el Muro de Berlín se convierte en motivo inspirador, como si fuera en sí mismo una obra de arte, a la vez que objeto de reflexión crítica. Cf. Javier Cano Ramos, ed., Wolf Vostell: Más allá de la catástrofe (arte igual a vida, vida igual a historia)(Cáceres: Museo Vostell Malpartida y Dirección General de Bibliotecas, Museos y Patrimonio Cultural de la Junta de Extremadura, 2016).

34. 1990, Museo Vostell Malpartida.

35. Wolf Vostell, La caída del Muro de Berlín (Mérida: Editora Regional de Extremadura, 2000). 
se quiere, la columnata de la escena emeritense aparece como una transmutación del monumento alemán, evocando su iconografía, de forma que, a través de la trama de Esquilo, 7 contra Tebas se presenta como reflexión sobre la catástrofe humana que surge de la división, de la separación. Y es que también la imagen de la puerta se ve quebrada por un golpe de pintura roja que deshace la imagen, como desangrándola ${ }^{36}$.

A lo largo de su biografía creativa Vostell va demostrando un profundo dominio de los temas y estética que lo definen, hasta el punto de que es capaz de hacer continuas variaciones sin resultar reiterativo, como revela el hecho de que a duras penas se podría hablar de obras mayores y menores, sino que todas constituyen un tejido autorreferencial que no impide la unidad de cada creación. De ahí que se haga necesaria una aproximación casi individualizada a cada una de sus obras; o, en otras palabras, un análisis obra a obra. El análisis hermenéutico deriva de un enriquecimiento del trabajo del pintor alemán, de su voluntad cosmopolita, de su profundo humanismo.

En definitiva, la propuesta de Vostell para la obra de Esquilo interviene sobre el espacio escénico como si las propias ruinas constituyeran parte del decollage que plantea el artista alemán, a la vez que en la propuesta no falta el icono del avión, recurrente en su poética personal. Tal es el argumento central de nuestro estudio y también de nuestra lectura personal: y es que, de haberse construido la escenografía, Esquilo y Vostell dialogarían acerca del drama de enfrentamiento civil que subyace en la trama, a la vez que se habría ampliado así la implicación del espectador en la representación teatral (como sucede con las obras Fluxus) y, finalmente, se hubiera producido la característica catarsis propia de la tragedia y del humanismo vostelliano.

\section{Referencias}

Bazán de Huerta, Moises, ed. Simposio Happening, Fluxus y otros comportamientos artísticos de la segunda mitad del siglo XX. Mérida: Editora Regional de Extremadura, Universidad de Extremadura y Consorcio del Museo Vostell Malpartida, 2001.

36. A este respecto, también es posible descubrir la influencia de Puerta de Cuchara (1990, Museo Vostell Malpartida), en la que una cuchara se impone sobre la imagen en blanco y negro de la puerta berlinesa. Por lo demás, en la magna Mythos Berlin (1986-1987, Museo Vostell Malpartida), el Muro constituye uno de los leit-motivs implicados de forma más evidente a la estética del artista. En fin, en Berlin (1990, Museo Vostell Malpartida), el Muro parece abrirse como las dos piernas, al igual que en Berlinesas $n^{0} 8$ (1990, Museo Vostell Malpartida) 0 en Quien esté libre de pecado que tire la primera piedra (1990, Museo Vostell Malpartida), de rica ironía polisémica, sobre los restos del Muro y sobre la puerta -al igual que en lo referido a Tebas-. Elementos concomitantes se descubren en Proyecto para la puerta de Brandenburgo (1991-1992, Museo Vostell Malpartida), donde la columnata de la puerta anticipa la frons scenae emeritense. Cf. Vostell, Caída, passim. 
Becker, Jürgen, y Wolf Vostell. Happenings. Fluxus. Pop Art. Nouveau Realisme. Eine Dokumentation Herausgegeben. Reinbeck bei Hamburg: Rowohlt Taschenbuch Verlag, 1965.

Cano Ramos, Javier, ed. Wolf Vostell: Más allá de la catástrofe (arte igual a vida, vida igual a historia). Cáceres: Museo Vostell Malpartida y Dirección General de Bibliotecas, Museos y Patrimonio Cultural de la Junta de Extremadura, 2016.

Castellari, Marco. Hölderlin und das Theater: Produktion - Rezeption - Transformation. Berlin: De Gruyter, 2018.

Cortés Morillo, Josefa. "Obra gráfica de Wolf Vostell(1959-1979)." Norba-Arte, no. 22-23(20022003): 239-260.

---. "Wolf Vostell: El concepto de "de-coll/age" en sus libros de artista." En Libros con Arte. Arte con Libros, editado por María del Mar Lozano Bartolozzi, Francisco Manuel Sánchez Lomba, Josefa Cortés Morillo, e Isabel María Sánchez Gajardo, 207-211. Cáceres: Consejería de Cultura y Turismo de la Junta de Extremadura.

Echandi Ercila, Santiago. La fábula de Aquiles y Quelone: Ensayos sobre Zenón de Elea. Zaragoza: Prensas Universitarias de Zaragoza, 1993.

Esquilo. Siete contra Tebas. Con versión y traducción de Jesús Alviz Arroyo, E. Díez-Canedo, y Concha Rodríguez. Madrid: Ediciones Clásicas, 1992.

Franco Rodríguez, Antonio, José Antonio Agúndez García, y Javier Cano Ramos. Vostell Extremadura. Mérida: Asamblea de Extremadura, 1992.

García Arranz, José Julio. "El azar como resemantizador de la obra de arte: A propósito de ¿Por qué el proceso entre Pilatos y Jesús duró sólo dos minutos?'." Norba-Arte, no. 27 (2003): 217-242.

Heyme, Hansgünther, y Wolf Vostell. Hamlet. Phöenizierinnen. Inszenierungsdocumentantion. Stuttgart: Württembergische Staatstheater Stuttgart \& Druckhaus Münster, 1982.

Lozano Bartolozzi, María del Mar. Wolf Vostell. Donostia-San Sebastián: Nerea, 2000.

Manresa, Andreu. "Obras Públicas desautoriza un proyecto plástico en faros de Ibiza al día siguiente de su presentación." El País, 25 de septiembre de 1992. Consultado el 3 de junio de 2019. https://elpais.com/diario/1992/09/25/cultura/717372004_850215.html.

Palomino Arjona, Manuel. Dramaturgia asturiana contemporánea. Índice biobibliográfico. Morrisville, North Caroline: Lulu Press, Lulu.com, 2019.

Riese, Hans-Peter. "Arc de Paix." En Wolf Vostell. Meine Kunst ist der ewige Widerstand gegen den Tod. Katalog, editado por Gabriele Ueisberg, 96-97. Bonn: Rheinisches LandesMuseum, 2007.

Ronte, Dieter. "Kriegskreuzigung/War Crucifixion". En Wolf Vostell. Meine Kunst ist der ewige Widerstand gegen den Tod. Katalog, editado por Gabriele Ueisberg, 6-9. Bonn: Rheinisches LandesMuseum, 2007.

Ruhé, Harry. Fluxus. The most radical and experimental art movement of the sixties. Amsterdam: A Verlag, 1979.

Smith, Owen. Fluxus: The History of an Attitude. San Diego, CA: San Diego State University Press, San Diego, 1998.

Somerstein, Alan H. Aeschylean Tragedy. London: Duckworth, 2010.

Steiner, Georges. Antígonas. Una poética y una filosofía de las lecturas. Barcelona: Gedisa, 1996. 
Torrance, Isabelle, ed. Aeschylus and War: Comparative Perspectives on Seven against Thebes. London \& New York: Routledge, 2017.

Vogel, Marlen. Das illusorische Theater und die Kunstbewegungen Happening und Fluxus. München: Grin Verlag, 2007.

Vostell, Wolf. La caída del Muro de Berlín. Mérida: Editora Regional de Extremadura, 2000.

---. Impresiones. La colección de obra gráfica del Archivo Happening Vostell del Museo Vostell Malpartida. Catálogo. Mérida y Malpartida de Cáceres: Editora Regional de Extremadura y Consorcio del Museo Vostell Malpartida, 2008.

---. Carteles. Catálogo. Mérida y Malpartida de Cáceres: Editora Regional de Extremadura y Consorcio del Museo Vostell Malpartida, 2013. 